\title{
The Concept of Resource Use Efficiency as a Theoretical Basis for Promising Coal Mining Technologies
}

\author{
Vadim Mikhalchenko ${ }^{1 *}$ \\ ${ }^{1}$ T.F. Gorbachev Kuzbass State Technical University, 650000, 28 Vesennyaya St., Kemerovo, Russia
}

\begin{abstract}
The article is devoted to solving one of the most relevant problems of the coal mining industry - its high resource use efficiency, which results in high environmental and economic costs of operating enterprises. It is shown that it is the high resource use efficiency of traditional, historically developed coal production systems that generates a conflict between indicators of economic efficiency and indicators of resistance to uncertainty and variability of market environment parameters. The traditional technological paradigm of exploitation of coal deposits also predetermines high, technology-driven, economic risks. The solution is shown and a real example of the problem solution is considered.
\end{abstract}

\section{Introduction}

The current development of the world economy is accompanied by ever-increasing demands for energy. At the same time, coal, as the energy base of the first industrial revolution, more and more is losing its ground to oil and gas, as more technologically sophisticated, cheaper and more environmentally friendly sources of hydrocarbon energy. Since the middle of the XX century, when the share of coal in the fuel and energy balance of Russia reached $65 \%$, it has been steadily declining and currently it is just only $12-13 \%$.

Add to this the modern period is characterized by an intensive quest for solutions to create efficient power plants based on alternative hydrocarbon sources. A number of forecast estimates indicate the near completion of the "era of hydrocarbons". According to the forecast of the famous futurist Ray Kurzweil, technical director of Google, by 2028 the "green" energy (sun, wind, water streams, geothermal sources) will become one of the key technologies for the development of all others. It will be approved as the dominant concept [1].

Expected scientific and technological breakthroughs in solar energy will allow to get a sharp drop in prices for solar panels by 2020 and reduce the turnkey price of solar power from $\$ 2.5$ to $\$ 0.8-1$ per watt, which will make possible to generate a "green" electricity at a lower price than currently it is possible to get the cheapest one from coal-fired power plants [2].

\footnotetext{
*Corresponding author: V.Mikhalchenko@mail.ru
} 
In this regard, the problem of increasing the efficiency and, consequently, the competitiveness of coal mining production, acquires an extremely high relevance and requires its solution.

\section{Materials and methods}

An analysis of the underlying causal factors that limit the opportunities for increasing the efficiency of open coal mining enterprises developing steeply falling, inclined and gently sloping coal deposits using technology with the use of a deepen-longitudinal development system (the currently widely used in open coal mining technology) has revealed the following two main prerequisites, which are underlying principles in decision-making, both at the design stage, and in practical activities in mining operations during the exploitation of coal deposits.

The first is the prerequisite of the "transfer of mined rock". According to which it is supposed that the technology includes extracting the rock mass, transporting it for a considerable distance and storing it outside the open-pit mines.

The second is the prerequisite of the "rigid geometry" of the quarry. In this case it is assumed that the quarry is formed as a certain geometric volume with a rigidly predetermined form and relations between the parameters of this volume. The deterministic development model is based on a rigid spatial-temporal relationship between the decisions of the current time period and the possible parameters of the quarry and coal mining technology in the very distant future, up to 50 years or more.

It is these two prerequisites, which implicitly present in most optimization tasks, form the structure of the relationship between the target characteristics (efficiency criteria) and the technology parameters. If to track the connections of these prerequisites, the following closed logical structure is revealed: the principle of "transfer of mined rock" is predetermined by the principle of "rigid geometry" of the quarry; in turn, the "rigid geometry" of the quarry is a consequence of the requirement to maximize the extraction of balance reserves; the estimation of reserves is carried out, proceeding from the precondition of technology application based on principles of "transfer of mined rock" and "rigid geometry" of the quarry.

The realization of these prerequisites generates a high resource use efficiency of coal production (the cost of resources reaches - fifty percent or more in the structure of costs in the coal mining enterprises), its high inertia and high technologically caused economic losses and risks, and as a result, it limits the realization of the possible potential of the open coal mining efficiency.

Among the noted characteristics, it is necessary to highlight such an important in the present circumstances economic parameter as a risk.

In the management literature, the risk is interpreted as the possibility of undesirable deviation from the goal, which the management entity seeks and for the sake of which it invests its resources in the business.

The definition of uncertainty is closely related to the definition of risk. Uncertainty is described as incompleteness of knowledge about the factors that affect the possibility of achieving the goal. In this interpretation, uncertainty acts as a causal factor, as a prerequisite for the emergence of risk. Or, if to use a figurative definition, uncertainty is a habitat for risk. It is obvious that the higher the level of parameters variability of the economic environment, the higher the uncertainty, and, consequently, the risks.

At the design stage of the future enterprise, the initial information uncertainty has the highest possible values, i.e. our knowledge of the parameters of the market environment in the future is zero and, consequently, the probability of a wrong decision is exceptionally high. In this case 
decision making will be similar to random actions, that is, the possibility of making the wrong decision is very high, and thus the risk of error with negative consequences is very significant.

This is very important for the development of the theory and practice of open coal mining. The fact is that economic losses and risks start to form at the stage of project development of the future enterprise, when a set of components of the production system is determined and connections between them are established, i.e., the basic constructive decisions are made and the structure of the future enterprise, its main parameters and characteristics are determined. At the same time, the basis for theoretical approaches to determining the parameters of currently operating enterprises is based on the above prerequisites in the form of a basic methodological principle of an "one-off" optimization of all constructive and production solutions distributed throughout the life cycle of an enterprise, the duration of which, based on the size of industrial reserves and the normative values of production power, is generally 50 or more years. From the point of view of optimization theory, the use of this principle can be interpreted as an attempt to build an optimal trajectory of the enterprise for many years ahead with a rigid fixation of the final state of this trajectory. At the same time, when it comes to the development of gently sloped, inclined and steep deposits, the ultimate depth of open development is the fundamental parameter that determines the entire set of cause-effect technical, technological, organizational, managerial and economic relations of an open coal mining enterprise.

Thus, we are talking about a "rigid" spatial-temporal fixation of the boundaries of the quarry at the time of mine abandoning, determining the parameter of which is the final depth of the quarry, is chosen "optimally" at the design stage for a very remote perspective, based on the condition of the maximum net discounted income for the whole life cycle of a coal mining enterprise.

Decision making on the final boundaries of the quarry, which should be achieved, as already noted in 50 years or more, determines and limits within the whole life cycle such structural relationships and economic parameters of the enterprise as the dependence of the transportation distance of the mined rock and the current stripping ratio, variable costs and production assets of the enterprise from the current and maximum depth of the quarry.

The fact is significant that the "rigid" fixation of the boundaries of the quarry along the surface across the strike and, as a result, the "rigid" spatial fixation of the overburden dumps location is a source of significant losses, the appearance of which is determined by design decisions. These decisions predetermine the occurrence of additional operating costs for moving host rocks beyond the outline of the final position of mining operations at the initial and medium stages of the enterprise's life cycle, i.e. for many decades, in the interests of coal mining in very remote periods of exploitation in the development of steep and, in the case of placement of rock dumps from the hanging side of the deposit, inclined and flat coal seams.

In addition, the specificity of forming the parameters of the quarry working area, predetermined by the need to withstand the angle of the slope of the working side within 15$20^{\circ}$, is such that it is necessary to make additional current investments in capital mining and overburden work carried out in the interests of "future periods". This predetermines an increase in these losses, in the form of an additional expenditure of resources, as well as a high inertia of the production system, which, under conditions of low reliability of the forecast of economic parameters of the external environment, generates significant economic risks.

As a result, the effect of "high resource use efficiency" and "technologically conditioned" capital linking is realized, and thus the conflict of "effectiveness-risk" criteria proves to be predetermined and embedded in the production system long before its appearance, even at the stage of its design, at the stage of making decision on final boundaries of open-pit mining, production capacity, parameters and direction of development of the working area and, as a consequence, parameters of production processes [3]. 
The use of the above methodological approach at the design stage of the enterprise is predetermined by the above, as well as by the economic prerequisites typical for the conditions of a centralized planned economy, which are basic: high stability and predictability of business environment parameters, guaranteed sales and payment for all goods produced, low value of economic criteria, availability and low cost of capital use.

However, at the present stage of the development of a market economy, it is necessary to review historically established "rules of the game", i.e. the paradigm that determines the rules and principles of open mining. At the same time, the most promising search directions are based on the revision of historically developed approaches to designing the main parameters of quarries and the rejection of the prerequisites such as "transfer of mined rock" and "rigid geometry" of the quarry.

\section{Results and discussion}

Consideration of current trends in the development of open-pit mining technology confirms what mentioned above. First of all, it concerns the revision of the principle of "transfer of mined rock". In the literature, technological schemes that are based on limiting the operation of this principle have been described for a long time back. It was most clearly reflected in technological schemes based on the placement of stripping within the open-pit (a block method for the development of coal strip mine and a transverse development system). However, these technologies have not been disseminated in practice, because could not provide a qualitative improvement in the indicators of environmental and economic efficiency in the initial period of coal field operation. Analysis of recent publications reveals a clear revival of the interest of scientists and practitioners to this type of technological solutions.

It is characterized by studies aimed at eliminating shortcomings inherent in these schemes, due to the simultaneous refusal of the prerequisites of the "transfer of mined rock" and "rigid geometry" of the quarry. In particular, the deep-solid transverse development system, protected by the copyright certificate [4], is based on the transition to the principle of "flexible", adaptive tactics of forming the geometry of the quarry, with a complete rupture of the rigid connection between the future quarry parameters and current period decisions, which makes it possible to implement internal dumping since the first years of coal field operation, to significantly reduce the distance of overburden transport and, as a result, to provide a significant reduction the resource intensity of production and the increase in economic and environmental efficiency.

The essence of technology is as follows. The development of a coal seam or series starts from the flank of the open field. In this case, the area of overburden and mining operations are located across the deposit bedding, move it along the line of its strike in the direction of the opposite flank of the quarry field (Figure 1).

The overburden from the first stope is laid on the surface in front of the working side 3 quarry, and after the coal is extracted and the initial capacity is created, the stripping rocks and the temporary dump are placed in the formed goaf 4, filling it.

The formation which is suitable for reclamation is removed from the territory which is spoiled by mine workings and applied to unused surfaces of the internal dump 5 .

Deepening of mining operations is carried out step by step through the cutting of new horizons through gaps that provide the formation of the bottom of the 6 quarry with the front-to-back slope $\alpha_{\text {д. }}$. The front-to-back slope of the quarry bottom is determined from the condition of ensuring the stability of the internal dump.

Before the beginning of the backfilling of the internal dump, a slope of the shaft 7 is constructed on the specially created path on the bottom of the quarry from the soil side of the formation, later blocked by a dumping massif. Underground preparatory workings 9 are carried out to extract the conserved reserves of minerals 8 from under the dump from the 
shaft. The coal is extracted by technology with the laying of the worked out space, which prevents deformation of the reclaimed surfaces of the internal dump.

Crushed stripping rocks can be used as a packing material. The minerals mined by the underground method are transported by conveyors through workings 9 and shaft 7 to
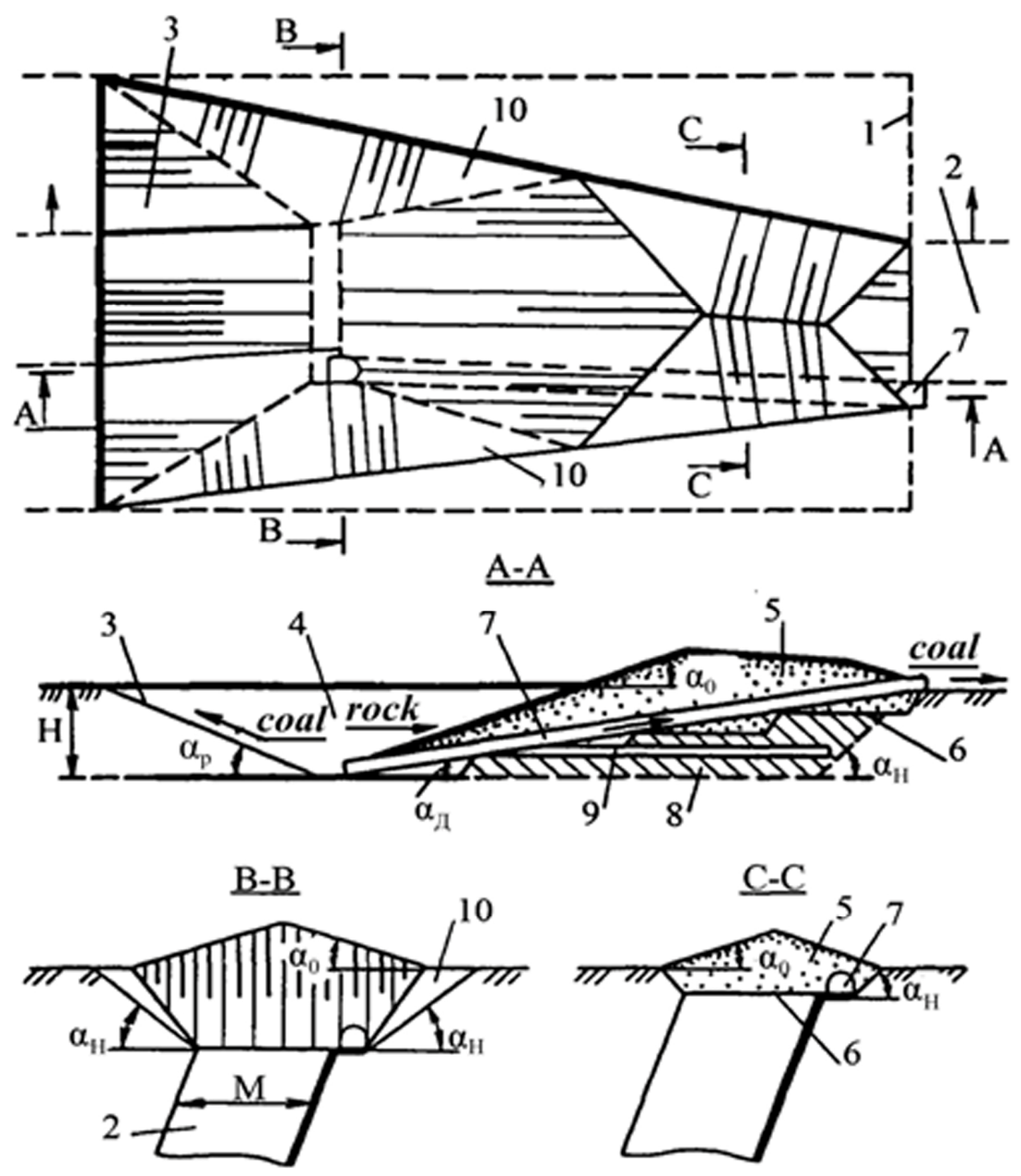

Fig. 1. Technological scheme of mining the deposit with the deepening of mining operations along the line of its strike and the continuous reclamation of the surface.

the surface. With moves forward and deepening of open mining operations, the length of the slope of shaft is increased, and new excavation fields are cut at a greater depth.

The overburden removal from working horizons of the quarry is carried out by dump trucks through haulage bench along the non-working sides 10 to the corresponding stage of the internal dump. The temporary automobile exits are being built for the moving of minerals from the quarry on the working and non-working sides. The processing of lower ledge is worked by a backhoe type excavator with its placement and vehicles on the upper platform, which excludes finding equipment at the bottom of the quarry and the danger of its damage by rock slipping down the slope of the lower stage. Lowering of mining operations is carried out to the final depth $\mathrm{H}$, after which the quarry operates with constant 
parameters of the working zone. At this stage the technogenic surface acquires a smooth terrain and is lowered practically to the level of the surrounding territories, which makes it suitable for creating highly productive agricultural lands. In case of revision of the lower boundary of effective development of a layer by an open method, a further depth of the quarry is made by cutting the subsequent horizons.

The reduction in the transportation distance of the mined rock due to a change in the direction of cargo flows is typical for "adaptive" development systems, since in this case a technological scheme with practically $100 \%$ internal dumping is provided, which gives a significant increase in the dynamic characteristics of the production system. The duration of the production cycle in comparable geotechnological conditions with the use of "adaptive" systems can decrease several times in comparison with the currently used deepenlongitudinal development system. The presence among corporate associations of coal enterprises that use "flexible" and "adaptive" development systems will allow servicing more than $90 \%$ of market demand in the "just in time" mode.

In addition, it is necessary to emphasize the fact that increasing the efficiency of open coal mining will create the conditions for revising the decision on the final boundaries of the quarry towards their significant increase in depth and, thus, expanding the resource base of open coal mining.

The conducted studies have shown that the considered option of the deep-open transverse system of open development ("flexible" technology) also allows eliminating the conditions for the emergence of high technologically-caused economic risks, stabilizing the mining regime, significantly reducing the negative impact of mining production on the environment and very significantly, in connection with a multiple reduction in mass transfer, reducing the resource intensity of production.

This is fully in line with the worldwide trends in the development of various industries, as, in particular, one of the reports to the Club of Rome [5], which justifies the concept of "resource productivity" and the relevance of issues of significant reduction in resource consumption. In addition, the proposed approach coincides with the dominant direction of development of modern production systems in various sectors of the economy and, in particular, with the concept of creating "lean" production systems $[6,7]$.

The noted positive characteristics of the deep-continuous transverse development system make it possible to consider it as a basis for the creation of coal-mining enterprises with a higher level of efficiency, ensuring the transition of the industry to the implementation of the strategy of resource and nature conservation, the strategy of economically efficient adaptation to the changing environmental conditions. At the same time, it should be emphasized that, in accordance with the fundamental principle of "correspondence of the level of complexity of the management system to the degree of variability of the management entity and its environment", effective implementation of the proposed "adaptive technologies" will require a transition to a qualitatively higher level of organization and management of coal mining.

It should also be noted that the deep-continuous transverse development system is only one of a large number of potentially possible options for implementing the principle of adaptive, evolutionary development of production coal mining systems, flexible development of the quarry. In accordance with the methodology of technical knowledge, the above result is achieved through transformations based on a change in the design of the production system, however, with the preservation of the structure of the technological chain, that is, preserving the traditional composition of the production processes of open coal mining.

However, an even greater effect can be achieved through transformations based on changes in the principles of building and operating coal mining systems. The transition to an open-underground coal mining method may be an example of such a solution [8]. Enlarged economic estimates show that in this case the efficiency can increase by more than 4 times. 
Obviously, under the influence of high competition in the energy market, the search for solutions and approaches that are enable further enhancement of the efficiency of open coal mining will continue.

\section{Conclusion}

The viability of socio-economic systems, as well as biological ones, is determined by their ability to adapt to the changed conditions of the external environment. With regard to production systems of open coal mining operating in uncertain and volatile conditions of the market environment, the transition to "flexible" adaptive models for the development of quarry will allow to come close to realizing the idea of resource saving and the concept of "lean production" and, as a result, to ensure a substantially higher profitability of production and the level of its environmental safety, which, undoubtedly, will enhance the competitive advantages of the coal-mining enterprises in the world energy market.

\section{References}

1. R. Kurzweil, The Six Epochs. In The Singularity Is Near: When Humans Transcend Biology. (New York: Viking, 2005)

2. D. Rifkin, The Third Industrial Revolution: How Lateral Power Is Transforming Energy, the Economy, and the World, 304 (St. Martin's Griffin, 2013)

3. V. V. Mikhalchenko, Y.T. Rubanik, IOP Conference Series: Earth and Environmental Science, 45, 012012 (2016)

4. V.V. Mikhalchenko, S.A. Prokopenko, V.G. Orlov, A.V. Koksin, Method for the development of stretched along the strike inclined and steeply falling deposits of high power, 25 (1992)

5. Factor Four: Doubling Wealth, Halving Resource Use: A Report to the Club of Rome, 320 (London: Earthscan, 1998)

6. V. Mikhalchenko, Y. Rubanik, N. Osokina, A. Mikhalchenko, The 8th Russian-Chinese symposium coal in the 21st century: mining, processing and safety, 10 (2016)

7. J. P. Womack, D.T. Jones, Lean thinking. Banish waste and create wealth in your corporation, 315 (New York, Free Press, 1996)

8. V.V. Mikhalchenko, A.A. Atrushkevich, The method of open-underground mining of stretched along the strike inclined and steeply falling deposits of high power, $\mathbf{3 5}$ (1999) 
